\title{
ASPECTOS CRÍTICOS E METODOLÓGICOS DOS ESTUDOS DE LIMA VAZ SOBRE O ETHOS
}

\author{
CRITICAL AND METHODOLOGICAL ASPECTS OF LIMA VAZ STUDIES ON \\ ETHOS
}

\author{
Magda Guadalupe dos Santos*
}

\begin{abstract}
Resumo
O reexame dos textos de H. C. de Lima Vaz, sob a ótica metodológica, possibilita certas variantes interpretativas acerca da complexidade e atualidade de sua leitura ética da cultura Ocidental. A despeito das contínuas interrogações sobre o sentido da universalidade conceitual, ao longo dos últimos séculos, a indagação sobre o sentido da dignidade da vida humana e seus valores ainda figura como tema de destaque, em várias chaves de leitura, nos debates filosóficos e jurídicos da atualidade. Este artigo ocupa-se das variantes metodológicas que sustentam possíveis correlações entre nómos e lógos como formas conceituais de discernimento de aspectos éticos em estrito senso, e das questões político-jurídicas que afetam a contemporaneidade.
\end{abstract}

Palavas-chave: Ética. Direito. Racionalidade. Método.

\begin{abstract}
The review of the texts by H. C. de Lima Vaz, from a methodological perspective, allows for certain interpretative variants about the complexity and timeliness of his ethical reading of Western culture. In spite of continuous questions about the meaning of conceptual universality over the past centuries, the question about the human dignity and its values still figures as a prominent theme in several reading keys, in the current philosophical and legal debates. This text deals with the methodological variants that support possible correlations between nómos and logos as conceptual forms of discerning ethical aspects in a strict sense, and the politicallegal issues that affect contemporaneity.
\end{abstract}

Keywords: Ethics. Law. Rationality. Method.

Artigo Submetido em 20 de Novembro de 2019 e aprovado em 15 de Fevereiro de 2020

* Professora Doutora do Departamento de Filosofia da Pontifícia Universidade Católica de Minas Gerais. PUC Minas; da Faculdade de Educação da Universidade do Estado de Minas Gerais. FaE.UEMG. Pesquisadora de filosofia e teorias feministas e éticas. Integrante do GT Desconstrução, Alteridade e Linguagem da ANPOF, desde 2010; Integrante da Simone de Beauvoir Society, desde 2010. Integrante do Conselho Editorial (Editorial Board) da Revista Simone de Beauvoir Studies, desde 2020. Email: magda.guadalupe@gmail.com 


\section{INTRODUÇÃO}

Este artigo é uma revisão atualizada de paper apresentado no $X$ Colóquio Vaziano, intitulado "Ética, Política e Direito: Urgência e Limites", organizado pela FAJE - Faculdade Jesuíta de Filosofia e Teologia, em 2017, e já publicado, numa primeira versão, em Annales, Belo Horizonte, v. 2, n. 2, 2017.

Naquela ocasião, o que se visava era correlacionar princípios políticos e jurídicos sob o prisma ético do pensamento de H. C. de Lima Vaz e demonstrar a sua efetividade em moldes metodológicos. O tempo registrado em conceitos, na esteira do velho Hegel, resultava naquele momento como uma hipótese a ser comprovada teoricamente. No presente artigo, alguns tópicos foram modificados com o intuído de pesquisar o nível crítico da trajetória ética do Ocidente.

A ancestralidade do pensamento de Lima Vaz inscreve-se em um dos mais significativos paradigmas que a filosofia ético-política brasileira pôde constituir. Sua obra, contudo, não se restringe ao conjunto de conteúdos éticos que incidem sobre questões de relevo histórico e que perpassam os "tempos sombrios" do complexo cenário brasileiro sob o peso da ditadura militar. Bem se sabe como certas arestas em torno ao vigor da democracia mostram-se novamente hoje com contornos bastante delicados. Se o grande lema da democracia dos Séculos XX e XXI se centra em torno da questão da igualdade, Vaz problematiza tal centralidade, especialmente em Democracia e Sociedade (1985), ressaltando o valor da "igualdade na diferença" como díade fundamental para o percurso dialético que subsidia a complexa relação entre ética e política (VAZ, [1985] 2000, p. 268).

Nesses termos iniciais, a complexidade da obra de Lima Vaz deve-se, sobretudo, à inteligência de sua abordagem dos problemas por meio de método que favorece um maior alcance dialético e fenomenológico, conceitual e hermenêutico-axiológico do lugar do sujeito histórico no palco das indagações éticas atuais. Se os tempos sombrios reconfigurados nos perseguem e se infiltram entre nós, recusando sobretudo o valor da logicidade e conhecimentos argumentativos, é preciso investigar quais os pilares que fortalecem a leitura lógica do mundo e o que nos resta da transmutação do logos grego.

Grande parte do privilégio de se ter frequentado aulas e conferências de Lima Vaz na velha FAFICH/UFMG, nas décadas de 1970 e 1980, de se ter aprendido com seus textos a sustentar o prazer de ler as complexas obras de filosofia e de ousar raciocinar e argumentar sobre elas, toda essa gama de privilégios possivelmente seja proveniente do modus operandi do pensamento que Lima Vaz nos legou. O filósofo ensina a pensar com devoção à 
materialidade do texto, assim como explorar níveis de leitura com diversas e interativas faces de ordenação sistemática. Usando desse método, suas investigações e interpelações filosóficas surgem bastante originais, enquanto alternativas hermenêuticas e axiológicas bem agudas, que se vão constituindo em torno das vicissitudes da razão moderna, que evoca os antigos gregos e chega ao mundo pós-hegeliano e até à contemporaneidade. Certamente, trata-se de uma façanha complexa, mas que aguça e provoca o senso crítico do que resta hoje do ser pensante. Possivelmente hoje, quando o cenário da velha paideia grega, do que resta da educação, esteja fragilizado pelas (anti)políticas estatais, repensar modos de ativar o raciocínio filosófico é um dos grandes desafios.

Não se pode imaginar que a leitura do mundo de Lima Vaz tenha encontrado uma pontuação final em 2002, época de sua partida deste "entre nós", justamente quando o século XXI acirrava seus debates éticos e (pós)-metafísicos acerca do sentido do ser e de todo o nosso existir historicamente. Em seus textos, depara-se tanto com a expressão de respeito e mesmo de exaltação da tradição filosófico-cultural, quanto com a urgência de se repensar a dinâmica dos tempos. Ademais, ajustando seu modo de redefinir preocupações formais e metodológicas, verifica-se como Vaz transmite o registro dialético do projeto cultural e pedagógico da história do Ocidente. Sua forma é também crítica, abrindo espaço para outros modos de repensar certezas fundamentais e todo o edifício simbólico que chega até nós, no momento crítico em que nos situamos hoje.

Como então relacionar o conteúdo e a forma em que se expressam a essência e a potencialidade, a profundidade textual e as preocupações formais em níveis metodológicos distintos? Como lidar ou operar com as questões da dialeticidade metodológica, que nos impulsiona sempre para os registros temáticos que saltam aos olhos indagativos e críticos de nós mesmas e mesmos? Tais registros assentam-se sobre um mundo que fabrica princípios e valores universais, mas trabalha de forma relativizada com as revisões críticas da amplitude conceitual e valorativa de fatos e tópicos pontuais que nos cercam. Essas indagações nos acompanham desde o momento em que percebemos as sutilezas e complexidade metodológica do pensamento de Lima Vaz, que apontam para as exigências de acuidade de visão e reflexão; mesmo através de toda a mudança temporalizada, seu pensamento serve de propulsor lógico para continuar e mesmo insistir em firmar o olhar filosófico sobre o mundo.

Apresentam-se neste texto, de forma dialógica, dois aspectos importantes da filosofia de Lima Vaz, a saber: as questões conceituais sobre a relação entre ética e direito, sob o 
impacto da história da cultura e das novas teorias filosóficas do final do século $\mathrm{XX}$, e o relevo metodológico que sustenta tal tematização.

\section{RASTROS DO ETHOS DA MODERNIDADE}

Segundo H. C. de Lima Vaz, a importância do Direito na concepção históricoconceitual do Ocidente, seja como "jurisprudência efetiva" proveniente do mundo romano (VAZ, 2001, p.14), seja como “a razão da vida política” (VAZ, 2000, p.146-147), ganha ampla conotação na leitura hegeliana, enquanto campo "da liberdade realizada" (VAZ, 2000, p. 136). Para Vaz a leitura contemporânea sobre os alicerces valorativos ocidentais torna mais aguda a crise de crenças e certezas, as quais, desde o Renascimento, já se vão reformulando até chegar, no final do século XIX, ao que então se chama de "ilusão religiosa" e ganhar repercussão na filosofia da pós-modernidade. A crítica ao lugar do Deus transcendente e sua substituição por novos deuses, nomeadamente o progresso e o tempo, cultuados na "fruição obsessiva do presente" e na expectativa de um futuro melhor (VAZ, 2001, p. 20), sustenta leituras distintas, inclusive de certo exame niilista da vida que fere de morte o existir humano e provoca certa "anomia generalizada" no projeto antropocêntrico da modernidade (VAZ, 2001, p. 22). Isso porque, ainda segundo Lima Vaz, o "prodigioso aperfeiçoamento técnico da medida do tempo físico" passa a submeter-se ao tempo da técnica, do cronômetro, resultando no caminhar da vida para "o nada da morte", dispersando-se assim o enigma do tempo, que suportaria as interrogações acerca do "sentido da vida" ou mesmo do "existir humano", favorecendo-se, pois, as aporias do humanismo antropocêntrico.

Neste contemporâneo "reinado do homem" (VAZ, 2001, p. 22) - que ouso entender também como um reinado dos homens -, ao qual todos devem se curvar e se mostrar subservientes, na sua "proliferação de ídolos" (VAZ, 2001, p. 22), evidencia-se não apenas uma intrínseca e complexa relação axiológica entre nómoi e lógoi (escrevo propositalmente no plural, por se tratar mais da pluralidade de formas lógicas e normativas de pensar), como também uma universal crise do sentido do humano. Segundo Vaz, na passagem do milênio tal crise abala "os fundamentos da nossa civilização", surgindo no tumulto "da cacofonia ideológica que ensurdece nossos ouvidos", para usar suas exatas palavras em "O Humanismo hoje" (VAZ, 2001, p. 22-23). 


\section{NOVAS INTERPELAÇÕES E ANALOGIAS CONCEITUAIS}

Do cultivo da crise de pensamento como algo próprio do ethos da variada cultura ocidental sobressai a concepção humanista, resultante de um dos mais destacados paradigmas antropológicos da cultura, e, em contrapartida, surgem as teorias que reexaminam as faces axiológicas de tal concepção. No contexto da tradição, tem-se, de uma perspectiva, o estudo metodológico proposto por Lima Vaz, que nos faz caminhar com apreço à história filosóficometafísica, por meio de correlações conceituais. Impõe-se também compreender qual o novo itinerário filosófico que nos remete às leituras das rupturas axiológicas na atualidade, as quais cultuam a crise do pensamento e giram em seu entorno na forma de novas propostas interpretativas e valorativas, como alternativas do pensar antropocêntrico moderno. Tal interlocução conceitual não seria possível se não pudéssemos contar e mesmo nos servir da metodologia sempre proposta por Lima Vaz na exposição didática de suas análises. Vale mencionar, para os leitores que apenas sobrevoam rapidamente textos e ideias, as rupturas valorativas do cenário filosófico contemporâneo são profundas e frutíferas, em nada se assemelhando ao rompimento proposto, no cenário ético-político da atualidade, de desprezo ao rigor lógico e conceitual. Uma coisa é problematizar o alcance do pensamento, outra coisa, bem distinta, é desautorizar formas cognitivas de pensar por serem perigosas ao modus operandi da política brasileira atual.

Em sua leitura conceitual e histórica, Vaz procede a uma abordagem interpretativa do ethos da cultura, que, de forma dialética, pode ser assumida de várias angulações, de acordo com o método proposto. Entre as correlações conceituais, especificamente na primeira parte de Ética e Direito (1977), vai-se do ethos à sociedade política, na gênese do direito, o que se apresenta como uma descrição de correspondências entre as medidas normativas da interioridade, "que regem a práxis do indivíduo", e a lei político-jurídica. Se, de certa angulação, tem-se o ethos como hábito cuja fundamentação lógica se concebe na doutrina da virtude (areté), de outra, nas teorizações e práticas do agir em comum, qualifica-se a doutrina da lei justa ou da politeía como o análogo da virtude no indivíduo. De modo dialético, a práxis individual encontra correspondência no direito enquanto representação da comunidade, devendo ambas as formas enfrentarem a desmesura (hýbris) do indivíduo, da sociedade e do próprio direito, por meio da codificação da liberdade consensual em bases sempre lógicas.

Podemos assim representar de forma esquemática tal analogia: 
Base da relação entre (ciência) ética // sociedade política Nómos (a lei lógica como base de tal analogia)

\begin{tabular}{|c|c|}
\hline $\begin{array}{c}\text { Lei ou medida interior segundo critérios de } \\
\text { qualidades/virtudes (aretai) }\end{array}$ & $\begin{array}{l}\text { Lei da cidade (constituída para um viver-em- } \\
\text { comum) }\end{array}$ \\
\hline $\begin{array}{l}\text { A base lógica do êthos: teoria do agir } \\
\text { individual: doutrina da virtude (areté) }\end{array}$ & Teoria do agir em comum. \\
\hline Ethos e métron de hábitos individuais & $\begin{array}{l}\text { Politeía como norma da comunidade e seus } \\
\text { costumes }\end{array}$ \\
\hline $\begin{array}{l}\text { O problema de uma razão (fundamento) da } \\
\text { liberdade }\end{array}$ & O problema da razão do livre consenso \\
\hline $\begin{array}{c}\text { As exigências éticas de um paradigma } \\
\text { normativo }\end{array}$ & $\begin{array}{l}\text { A Lei e o Direito como a realização plena da } \\
\text { prática consensual }\end{array}$ \\
\hline$\frac{\text { Orthòs lógos }}{\text { Indivíduo }}$ & $\frac{\text { Direito }}{\text { Comunidade }}$ \\
\hline um & eito \\
\hline
\end{tabular}

Com base nesse método analógico de representações valorativas, Vaz aponta os caminhos viáveis historicamente, tomando sempre como referência a base mensurativa enquanto o métron da virtude (areté) e da lei (nómos).

Ora, se pudermos adaptar essa correlação a um quadro de analogias flexíveis, cujos conteúdos se modificam ao longo do agir histórico, pelo menos em sua apreensão axiológica, verifica-se que a mobilidade interpretativa pode ser contemplada como respostas ao processo histórico do Ocidente. Constata-se que, nesse quadro normativo e sistêmico, ao se alterar historicamente a concepção hermenêutico-axiológica de alguns princípios e conceitos dispostos em uma das margens do quadro comparativo (que dispomos em letras, fontes e cores correlatas), necessariamente a outra margem também se modifica, provocando novas possibilidades de entendimento sobre o ethos, em sentido estrito, e sobre a politeia, enquanto base constitutiva e política de leis justas.

Desta feita, ao se tomar o desenvolvimento histórico e as respostas a serem oferecidas a partir dos seguimentos relacionais, assim como os abalos decorrentes de tais mudanças, as exigências éticas se mantêm, desde que o seu conteúdo valorativo possa sempre responder de forma lógica aos novos embates normativos da cultura. Para tanto, a reta razão (orthòs lógos) sempre deverá estar alinhada ao direito, como expressão máxima da racionalidade ética em 
sociedade. Os exemplos possíveis podem ser buscados na correspondência entre as mudanças do perfil antropológico e as novas concepções jurídicas daí decorrentes, bem como no impacto das leis sobre a compreensão e assunção de tais novas possibilidades de ser e existir em sociedade. Podem ser indicadas, como exemplo, no Brasil, as leis especiais que reconheceram a convivência more uxorio também como entidade familiar, a jurisprudência firmada acerca dos casamentos fora dos cânones da heterossexualidade obrigatória etc. como impacto dialético e reativo do ethos individual no nómos social.

\section{CRÍTICAS À TRADIÇÃO HUMANISTA: FOUCAULT E DERRIDA}

É importante verificar se tal quadro comparativo, proposto à luz do método dialético de Lima Vaz, seria resistente aos embates hermenêuticos da filosofia contemporânea, que critica inclusive propostas dialéticas. Nesse sentido, ao se tomarem, por exemplo, as teses de Michel Foucault, de Emmanuel Levinas e, especialmente, as de Jacques Derrida, constata-se que não há como se obliterar a crise dos humanismos, pelo impacto das novas axiologias da contemporaneidade. Em As palavras e as coisas (1961) e A História da Sexualidade (1976), Foucault nos lega uma leitura axiológica pós-humanista, com o entendimento de que a convicção da autonomia do sujeito não passa de uma ilusão, sobretudo, por seus efeitos ameaçadores ao próprio ser humano, tomado como suposto "inimigo" de si na forma de uma aparente emancipação e defesa da dignidade humana. O que teria surgido na história é que o ser humano se tornou cúmplice ou causa de sua própria opressão. Ao criar saberes, a humanidade permitiu-se ser redefinida historicamente por tais concepções, fazendo surgir daí sua relação com as riquezas, palavras e signos, dotando de complexidade específica toda a materialidade e os saberes empíricos em seu entorno. Em Foucault, o homem (termo por ele utilizado) é determinado, por se encontrar naturalizado e historicizado, e, em contrapartida, ele é condição de possibilidade do saber, surgindo como o "fundamento de sua finitude empírica" (SOUZA, 2002, p. 107).

Com tais bases axiológicas, Foucault rejeita o homem adotado pelos procedimentos de poder, tomando a moral do humanismo como um produto e um efeito de um estudo que toma o homem como senhor de si próprio. Este efeito, com todas as suas presunções, há de ser também o resultado de uma "vontade de verdade": será verdadeiro o homem autêntico e racional, como a única saída para todos os males (FOUCAULT, 2003, p. 357). Na criação forçada dessa realidade, pois ela é um poder sutilmente construído e empossado enquanto tal, surgem os desvios do olhar valorativo, voltando-o justamente sobre "o homem como uma 
invenção do poder”. Foucault faz a incisiva crítica aos valores do século XX, tais como o homem, a loucura, a clínica, a sexualidade, a prisão. Os objetos constitutivos do presente, que nos dizem o que somos e o que enfrentamos, são o efeito de uma divisão entre o saber, o poder e a verdade; são elementos fundamentais para o estabelecimento de nossa suposta normalidade. Em As Palavras e as coisas, ele alega:

\footnotetext{
“A história da loucura seria a história do Outro - daquilo que, para uma cultura é ao mesmo tempo interior e estranho, a ser portanto excluído (para conjurar-lhe o perigo interior), encerrando-o porém (para reduzir-lhe a alteridade); a história da ordem das coisas seria a história do Mesmo - daquilo que, para uma cultura, é ao mesmo tempo disperso e aparentado, a ser portanto distinguido por marcas e recolhido em identidades." (FOUCAULT, 2000, p. XXI).
}

Conforme M. Foucault, partindo-se "da experiência-limite do Outro" e rumando às formas "constitutivas do saber médico e, destas, à ordem das coisas e ao pensamento do Mesmo", o que se apresenta à "análise arqueológica" é todo o saber clássico, ou seja, a modernidade surge por meio desta "estranha figura do saber que se chama homem e que abriu um espaço próprio às ciências humanas" (FOUCAULT, 2000. p. XXI).

Em seus estudos, que relacionam seres e coisas, surge a história das condições do pensamento com base em relações de similaridade ou de equivalência e da ordem das coisas, recolhidas em identidades (Foucault, 2000, p. XX). Cria-se, a partir daí, a biopolítica do poder, apta a normalizar e a adestrar o corpo humano por meio de diversas instituições modernas, tais como a escola, a fábrica, a caserna, o hospital-hospício, a prisão, entre outras (FOUCAULT, 1988, p. 151).

De perspectiva desconstrutivista, a leitura ético-política da cultura ocidental é feita na última etapa da vida de Jacques Derrida. O filósofo argelino assume novo alcance interpretativo, ora subsidiado na filosofia de E. Levinas, em que o Outro surge com absoluta primazia, ora repensando a lei, o direito e a própria condição lógica do pensar humano. Especificamente, em Os fins do homem (1968), texto apresentado em Nova York, em colóquio internacional sobre filosofia e antropologia, Derrida critica tanto a onda antropologista e metafísica da tradição, especialmente a que se forma em torno das leituras de Hegel, quanto a onda anti-humanista. Na primeira onda, cita os filósofos que, no pós-guerra, sentiram-se impelidos a lerem Hegel da perspectiva antropologista, com certo "solo comum dos existencialismos, cristãos ou ateus, dos personalismos de direita ou de esquerda, do marxismo de estilo clássico" (DERRIDA, 1991, p. 155). Embora não de todo dissolvida, tais 
leituras antropologistas da história, especialmente por meio da retomada do pensamento de Hegel, Husserl e Heidegger, são criticadas pelas teorias filosóficas posteriores e surgem, no pensamento francês dos anos 1960, as leituras pós-humanistas. Especialmente, o que Derrida critica são as interpretações que visam distinguir o que ou qual seria o fim do homem? Para ele, há em todas as teorias um equívoco do fim, uma preocupação teleológica que marca de morte o próprio homem e, como um jogo de leituras, todas elas voltam-se a um encadeamento:

\footnotetext{
"O fim do homem é pensamento do ser, o homem é o fim do pensamento do ser, o fim do homem é o fim do pensamento do ser. O homem é desde sempre o seu próprio fim, isto é, o fim do seu próprio. O ser é, desde sempre, o seu próprio fim, isto é, o fim do seu próprio" (Derrida, 1991, p. 175).
}

Segundo Derrida, o que se pode daí compreender é que há uma verdadeira "redução do sentido", por meio de uma "atenção prestada ao sistema e à estrutura", cujos propósitos não se voltam a restaurar o motivo clássico do sistema, nem mesmo em sua "regulação teleológica em busca da alétheia e da ousía," que tentam reunir valores nos conceitos de essência ou de sentido, nem a apagar nem a destruir o sentido. De acordo com Derrida, o que se pode entender é uma intenção de "determinar a possiblidade do sentido a partir de uma organização 'formal' que não tem, ela própria, sentido" (DERRIDA, 1991, p. 175). Isso não significa que tais teorias não teriam sentido em si mesmas, mas que se rompia com o sentido anterior por meio de novas formas estruturais.

Segundo sua economia de entendimento, seria, então, preciso, buscar um "certo fora" do pensamento filosófico, em função do "todo do Ocidente com o seu outro", tanto em termos linguísticos quanto das relações etnológicas, econômicas, políticas etc. Esse seria o argumento da Desconstrução, para além, inclusive, da Destruktion proposta por Heidegger, que continua o "novo terreno sobre o solo mais antigo" (DERRIDA, 1991, p. 176). Trata-se de uma ruptura para com as leituras tradicionais do passado, que sempre recuperam novas formas de ser e de sentido do ser. Sua concepção é a de mudar de terreno, abrir-se à diferença nela mesma, de maneira descontínua, por meio de várias línguas, vários textos, simultaneamente e de forma plural, para escapar de uma leitura de "cumplicidade essencial" da metafísica e do humanismo, sob todas as formas (DERRIDA, 1991, p. 163), sem ter que recorrer "à verdade do ser" (DERRIDA, 1991, p. 164). "O próprio do homem” é ao que se deve então renunciar, já que "o pensamento do próprio do homem é inseparável da questão ou da verdade do ser" 
(DERRIDA, 1991, p. 164), como se pensar o homem fora de sua essência não fosse algo autorizado à filosofia (DERRIDA, 1991, p. 169).

Crítico dos pensamentos centrados na essência humana, na fixidez dos conceitos, Derrida se propõe a desconstrução da metafísica, questionando todo o pensamento do ser do ente como presença. A fala e a busca pelo significado referenciam a ausência da presença do objeto, do ser, do outro. É preciso ir além dessa dualidade de referendar a ausência como um vazio da presença, como um ponto que só se evidencia quando colocado junto ao seu oposto. De acordo com Derrida, esta é justamente a tarefa ética e que diz respeito ao acolhimento do outro, a uma total hospitalidade, e não à descrição de formas de ser e de agir em relação ao outro do eu, em que se mesclam regras da lei e concepções éticas de justiça que se vão alterando no tempo e no espaço.

Importa aqui, sobretudo, inspecionar o sentido de justiça e o seu tratamento conferido pelo Direito. Lembra o filósofo que "não se pode falar diretamente da justiça, tematizar ou objetivar a justiça, dizer isto é justo" e, ainda menos, "eu sou justo, sem trair imediatamente a justiça, senão o direito", já que, sempre ao se tratar da justiça, nomeia-se e indica-se, na verdade, o direito, ou mesmo a "força da lei" (DERRIDA, 2007, p. 17-18).

Nessa obra, Força de lei, especificamente na primeira conferência, de 1989, proferida na Cardozo Law School (Nova York), Derrida, retomando o pensamento de Pascal e de Montaigne, trata do argumento da autoridade: a lei é seguida não porque é justa, mas porque é lei, este é o "argumento místico de sua autoridade" (Derrida, 2007, p. 20-21). Derrida, contudo, entende que a Desconstrução se compromete com a exigência de justiça infinita e que chega até nós por meio de "idiomas singulares", tais como "Dike, Jus, Justitia, Justice, Gerechtigkeit"; tal justiça se endereça sempre a singularidades, à "singularidade do outro", embora com pretensão de universalidade (DERRIDA, 2007, p. 37). Tem-se para com a justiça uma "responsabilidade sem limites, excessiva, incalculável, diante da memória" e, assim também, a responsabilidade de lembrar sempre da relação entre "justiça, lei e direito, valores e normas", relação que nos legaram prescrições sedimentadas no tempo (DERRIDA, 2007, p. 36). Faz-se importante salientar que, se o direito não espera, se ele incide no presente e de imediato, já a justiça está sempre no âmbito do porvir; "há um porvir para ajustiça, e só há justiça na medida em que seja possível o acontecimento que, como acontecimento, excede ao cálculo, às regras, aos programas, às antecipações" Ou seja, "a justiça, como experiência da alteridade absoluta" (DERRIDA, 2007, p. 55) é a sua condição aporética: “A justiça, na 
medida em que ela não é somente um conceito jurídico ou político, abre ao porvir a transformação", (...) a refundação do direito e da política (DERRIDA, 2007, p. 55).

Com Derrida se caminha a uma incisiva exprobração ou análise de reprimenda ao logocentrismo ocidental. Se o termo ou o seu significado é tomado por Lima Vaz como construtivo de um perfil lógico e normativo de eficiência e cuidados histórico-culturais, tal como se observa em Ética e Ciência (1971), em Derrida este já ganha certa projeção crítica. O logocentrismo ou o fonofalogocentrismo demonstrar-se-ia nos privilégios da voz sobre a escrita, do poder fálico e viril sobre o existir plúrimo e no feminino, de certo exagero do Ocidente em não medir esforços de aculturar outros saberes, outras formas marginais de vida e que Fernanda Bernardo (1992, p.155; 157-189) referenda como "desmantelamento dos mitos solidários na tessitura da história da Metafísica da Presença". . Esta é uma das pontuações críticas que surge desde Gramatologia (1967) e se estende ao conjunto de sua obra. Derrida entende que a história da metafísica sempre "atribuiu ao logos a origem da verdade em geral" e tal "história da verdade em geral" foi sempre "o rebaixamento da escritura e seu recalcamento fora da fala plena" (DERRIDA, 1973, p. 4). Assim, em novas bases axiológicas e hermenêuticas, Derrida torna expressiva a crítica a uma tradição de imposição de saberes e habitualidades, e que se mostraram sempre pouco afeitos ao outro e à diferença.

\section{SOCIEDADE POLÍTICA E ÉTICA}

A questão que desejo propor de novo e em novo viés histórico, é se tais pontuações críticas, que se voltam para o patrimônio metafísico e humanista da tradição - dele tendo-se servido como algo imprescindível para sua efetiva expressão, em bases lógicas e axiológicas -, poderiam ou não se adaptar às mudanças paradigmáticas do método de análise de Lima Vaz, na analogia entre ética e direito. Indaga-se se, tomando as alterações éticas, necessariamente teremos novas disposições na sociedade política e vice-versa, já que os filósofos contemporâneos partem tanto das relações políticas, quanto do ethos que se altera na pós-modernidade.

Assim, verifica-se novamente, mas com novas analogias, o quadro referencial abaixo.

\footnotetext{
${ }^{1}$ Segundo M. Fernanda Bernardo, o logocentrismo do pensamento ocidental foi arguido e desconstruído por Derrida, por meio de sincategoremas, tais como rastro, diferença, espaçamento, margem, sublinhando a estrutura indecidível que traz em si o valor duplo e contraditório de toda a marca ou signo, e que são o sentido e a racionalidade do discurso instituído, uma religião da linguagem como sentido, a busca do fundamento, da identidade e da homogeneidade.
} 


\section{A base da relação entre ethos e sociedade política \\ Nómos (a lei como base de tal analogia)}

\section{Alterações possíveis?}

\begin{tabular}{|c|c|}
\hline $\begin{array}{c}\text { Lei ou medida interior segunda critérios de construçãu do } \\
\text { saber (Foucault) e qualidades/virtudes (areta) }\end{array}$ & $\begin{array}{c}\text { Lei da cidade (biopolítica de determinação corpórea) } \\
\text { (Foucault) }\end{array}$ \\
\hline $\begin{array}{c}\text { Base lógica do e thos x imposição do mesmo x } \\
\text { outro (Levinas) }\end{array}$ & $\begin{array}{c}\text { Impossibilidade uma teoria do agir em } \\
\text { comum nos moldes dialéticos }\end{array}$ \\
\hline $\begin{array}{c}\text { Ethos: o outro e o diferente tomados em } \\
\text { sua singularidade específica }\end{array}$ & $\begin{array}{c}\text { Crítica ao fonologocentrismo: Leis e } \\
\text { direito como artifícios normativos } \\
\text { místicos e assumidos como válidos x } \\
\text { crenças de justiça (Derrida) }\end{array}$ \\
\hline \multicolumn{2}{|c|}{ X hýbris do próprio poder e a desconstrução de sua mitificação. } \\
\hline
\end{tabular}

Se as analogias realçam novas formas de retomar as díades ética e política, ética e direito, ética e justiça, estas se abrem a perspectivas críticas não apenas da tradição ou de suas possibilidades interpretativas, mas de nós mesmas e mesmos como intérpretes e artífices do mundo que criamos. Mantém-se a indagação se as mesmas bases metodológicas propostas por Vaz servem realmente de anteparo para a cognição do pensamento pós-metafísico da segunda metade do século XX. Ou, de outro modo, se fora das vias metodológicas propostas por Vaz poder-se-ia ler e compreender tais possibilidades interlocutivas com a mesma convicção, ou se até mesmo o método teria sido desconstruído na contemporaneidade?

De fato, ao reler os filósofos contemporâneos, críticos tanto do humanismo quanto da metafísica, pontuamos, com Levinas, em O Humanismo do novo homem (1972), que as formas tradicionais de pensar "a humanidade do humano", por meio de um discurso insustentável, tem se portado bem mais como forma de recusa e negação do que de estudos ou análises. Escreve Levinas: "tomar princípios de método por afirmações sobre o fundo das coisas (se é que o fim da metafísica permite ainda falar sobre o fundo das coisas)" é, com certeza, "o fato de espíritos simples e apressados" (LEVINAS, 1993, p. 110).

O que Lima Vaz possibilita são tematizações profundas que nos fazem acordar do sono condicionado pelas variantes de vozes, interesses e poder. Sem querer discordar do entendimento de Levinas, o que tentamos buscar em Lima Vaz é justamente a sutileza metodológica que nos faz firmar certezas e valores, sem nos perder em variantes de impressões e conjecturas. Contudo, seriam tais métodos analógicos simples disposições apressadas de certezas lógicas? 


\section{APONTAMENTOS FINAIS}

Se a filosofia contemporânea nos aponta criticamente o traçado metafísico e humanista que alenta o primado da filosofia no Ocidente, realça também o paradoxo, a diferença, como rastros que nos levam a ampliar o olhar para além do lógico, para o indecidivel interpretativo. A indagação que resiste é: como saber justificar as escolhas valorativas pelas vias que seguimos na filosofia?

O que o pensamento de Vaz nos lega é justamente o encontro das vias de possibilidades. Se conceitos e regras para uma leitura filosófica da história não se fazem mais realçar no século XX, certamente os níveis de leitura em que um texto filosófico merece ser lido e apreendido ainda têm lugar no respaldo de compreensão da filosofia. Sem ele, não se teria como pertinente ou válida a sustentação do caminhar indagativo da textualidade. Assim, retomando a afirmativa de nosso filósofo em uma conferência proferida em seção da SEAF, em 1982, intitulada "Por que ler Hegel hoje?" (VAZ, 1982, p .61-62), podemos indicar que, da materialidade do texto, que realça o problema de sua autenticidade e do rigor e possibilidades de comunicação, transitando pela leitura histórica, que pressupõe a ligação do texto com as experiências de vida de quem o escreve e com o que se escreve em sua época, chega-se até uma leitura hermenêutica, na qual cada um/a de nós vê-se interpretado/a pelas instâncias teóricas de sua situação histórica.

Vivemos tempos inglórios de descaso com o outro, com a pólis e com o ethos, em que alguns se julgam deuses e não homens, enquanto outros, supostos grandes-homens, fogem de Deus ou o perseguem com finalidades escusas, signos de irrelevância ou vontade de poder. Tempos falogocêntricos, possivelmente (ouso acreditar), de uma biopolítica exacerbada, mas, ainda assim, tempos em que a dominação como forma de violência e do absurdo só pode ceder lugar ao reconhecimento, sobretudo o reconhecimento moral das diferenças e do mínimo ético que nos sustenta, quando se souber distinguir, de alguma forma, seja pela recuperação crítica da metafísica ou do humanismo, seja pela desconstrução de falsos saberes e vozes inautênticas, qual é a forma mais apropriada de se lidar com a razão e com a liberdade.

Se, no Brasil de hoje, igualdade e diferença são termos pouco intercambiáveis, seria necessário rever o alcance axiológico e hermenêutico de tais conceitos e refazê-los no intento de uma "justiça do porvir", tal como indica Derrida em Força de Lei. Se o direito não espera, a justiça, por sua vez, só se anuncia como um porvir. Esperemos, pois, por tempos mais 
justos, em que a recusa do conhecimento não possa imperar, tempos em que a dignidade humana possa se fazer sempre significar.

\section{REFERÊNCIAS}

BERNARDO, M. Fernanda. O dom do texto. Revista Filosófica de Coimbra. Vol I. no. 1. Março de 1992, p. 155-189.

DERRIDA, Jacques. Força de Lei. O “fundamento místico da autoridade". Tradução de Leila Perrone-Moisés. São Paulo: Martins Fontes, 2007 (Tópicos)

DERRIDA, Jacques. Gramatologia. Tradução de Miriam Chnaiderman e Renato Janine Ribeiro. São Paulo: Perspectiva, 1973 (Estudos;16).

DERRIDA, Jacques. Margens da Filosofia. Os fins do Homem. Tradução de Joaquim Torres Costa e Antônio M. Magalhães. São Paulo: Papirus, 1991. p.149-178.

FOUCAULT, Michel. As palavras e as coisas. (Foucault, palavras e as coisas, Tradução de Salma T. Muchail. 8. ed. São Paulo: Martins Fontes, 2000.

FOUCAULT, Michel. História da Sexualidade: a vontade de saber. Rio de Janeiro: Edições Graal,1988.

LEVINAS, Emmanuel. Humanismo do outro homem. Tradução de Pergentino S. Pivato (Coord.). Petrópolis: Vozes, 1993.

SOUZA, Fabiane Marques de Carvalho. (Desconstrução do Humanismo: Foucault e Derrida. In: Duque-Estrada, Paulo César. Às margens. A propósito de Derrida. Rio de Janeiro: PUC-Rio editora, 2002. p.103-116.

VAZ, H.C. de Lima. Democracia e Sociedade. In: VAZ, H.C. de Lima. Escritos de Filosofia II. 3. ed. São Paulo: Loyola, [1985] 2000, p. 263-273.

VAZ, H.C. de Lima. Ética e Ciência. In: VAZ, H.C. de Lima. Escritos de Filosofia II. São Paulo: Loyola, [1974] 2000, p.181-224.

VAZ, H.C. de Lima. Ética e Direito. In: VAZ, H.C. de Lima. Escritos de Filosofia II. 3. ed. São Paulo: Loyola, [1977] 2000, p.135-180.

VAZ, H.C. de Lima. Humanismo hoje: Tradição e Missão. Belo Horizonte, PUC Minas, Instituto Jacques Maritain, 2001, p.7-27 (coração informado 5).

VAZ, H.C. de Lima. Fenomenologia e axiologia da modernidade. In: Vaz, H.C. de Lima. Escritos de Filosofia VII. Raízes da modernidade. São Paulo: Loyola, 2000, p.11-30.

VAZ, H.C. de Lima. A metafísica em questão. In: Vaz, H.C. de Lima. Escritos de Filosofia VII. Raízes da modernidade. São Paulo: Loyola, 2002. p.95-103.

VAZ, H.C. de Lima. Por que ler Hegel hoje? Belo Horizonte, Boletim SEAF, 1982. p.61-75. 